\title{
Prevalence and predictors of sleep apnea in patients with stable coronary artery disease: a cross-sectional study
}

This article was published in the following Dove Press journal:

Therapeutics and Clinical Risk Management

18 August 2017

Number of times this article has been viewed

\author{
Audrius Alonderis' \\ Giedrius Varoneckas' \\ Nijole Raskauskiene ${ }^{2}$ \\ Julija Brozaitiene' \\ 'Laboratory of Clinical Physiology and \\ Rehabilitation, Behavioral Medicine \\ Institute, Lithuanian University of \\ Health Sciences, Palanga, Lithuania; \\ ${ }^{2}$ Laboratory of Psychosomatic \\ Research, Behavioral Medicine \\ Institute, Lithuanian University of \\ Health Sciences, Palanga, Lithuania
}

Correspondence: Audrius Alonderis Laboratory of Clinical Physiology and Rehabilitation, Behavioral Medicine Institute, Lithuanian University of Health Sciences, Vyduno str. 4, Palanga, LT-00I35, Lithuania

Email audrius.alonderis@Ismuni.It
Background: Sleep apnea (SA) is increasingly recognized as being important in the prognosis of patients with coronary artery disease (CAD); however, symptoms of SA are not easily identified, and as many as $80 \%$ of sufferers remain undiagnosed.

Aim: This cross-sectional study investigated the prevalence and predictors of SA that may help to increase the awareness and diagnosis of SA in stable CAD patients.

Materials and methods: Polysomnography was performed in 772 medically stable CAD patients with untreated SA recruited from the Clinic of Cardiovascular Rehabilitation. Patients were predominantly male (76\%), median age was 58 years (32-81). All subjects completed the Epworth sleepiness scale (ESS). The frequency of all apneas and hypopneas associated with $3 \%$ oxygen desaturation is referred to as the apnea-hypopnea index (AHI). Mild-to-severe SA was defined as AHI $\geq 5 / \mathrm{h}$, moderate-to-severe SA as AHI $\geq 15 / \mathrm{h}$.

Results: AHI was within a range of values that was considered normal or only mildly elevated. The median AHI was 3.4 (interquartile range [IQR 1-9]), and 39\% of patients had unrecognized mild-to-severe SA (moderate-to-severe in 14\%), which was not higher than other known risk indicators for CAD such as hypertension and obesity ( $83 \%$ and $47 \%$, respectively). These patients did not show sleepiness and the risk-related cut-off score for excessive daily sleepiness was lower than the official for ESS.

Conclusion: Hypertension, age, male gender, obesity, ESS $\geq 6$, and left ventricular ejection fraction $\leq 45 \%$ were the best predictors of mild-to-severe SA. While, male gender, age 50-70 years and, mainly, the presence of obesity but not hypertension were clinical predictors for moderate-to-severe SA. In addition, association between mild-to-severe SA and obesity was not evident in women. SA is prevalent comorbidity in the stable CAD patients, especially in its asymptomatic mild form. We suggest that SA should be considered in the secondary prevention protocols for CAD.

Keywords: apnea-hypopnea index, AHI, age, CAD, gender differences, sleep apnea

\section{Introduction}

Recently, sleep-disordered breathing (SDB) has gained attention in the field of cardiology and is increasingly recognized as a novel cardiovascular (CV) risk factor. ${ }^{1-9}$ SDB and the related clinical syndrome, sleep apnea (SA), describe a group of disorders characterized by abnormalities in the frequency and/or depth of breathing while asleep. The syndrome of SA is associated with excessive daytime sleepiness or chronic fatigue. ${ }^{1,2}$ Patients with SA may also present major CV risk factors, such as hypertension, diabetes mellitus, dyslipidemia and obesity or overweight that all can affect cardiac structure and function. ${ }^{3,4}$ Thus, SA and these risk factors may explain 
the increased prevalence of coronary artery disease (CAD) in patients with SA. ${ }^{3,5}$ Furthermore, the prognosis of subjects with CAD could be affected by the presence and the severity of SA. ${ }^{6}$

As data supporting a causal role of SA in medical complications continue to increase, a concerted effort by health care professionals across specialties is needed to recognize those that remain undiagnosed. ${ }^{7}$ It is important that clinicians are aware of the various ways in which SA may manifest in their specialty, as in some cases, treatment of the SA results in an improvement in or even complete resolution of these symptoms. ${ }^{8}$ The SA might present to cardiologist (non-sleep specialist) with hypertension, left ventricular hypertrophy, nocturnal angina, myocardial infarction (MI), arrhythmias, heart failure, increased pulmonary artery pressure. ${ }^{9}$ Echocardiographic studies have shown both systolic ${ }^{10}$ and diastolic ${ }^{11}$ dysfunction with increasing SA severity. Waiting times for in-hospital polysomnography (PSG), which still represents the gold standard for SDB diagnosis, are increasing. Nocturnal PSG is essential for diagnosing SDB but it is time and energy consuming and the equipment and expertise to run it is not widely available.

In addition, it is unknown if the thresholds for diagnosing and treating SA should be the same in people with CV disease and those who are otherwise healthy, ${ }^{12}$ or if the presence of SA changes the effect of traditional risk factors for $\mathrm{CV}$ events and mortality. At present, the consequences of untreated mild or asymptomatic SA are unknown.

The purpose of our study, therefore, was 2-fold: first, to determine whether routine clinical features could predict the presence of SA by 2 thresholds for diagnosing (AHI $\geq 5$ and $\geq 15$ ); and second, to determine whether there are differences in risk factors for SA between men and women with stable CAD.

\section{Ethics approval and consent to participate}

The study and its consent procedures were approved by the Lithuanian Bioethics Committee (Certificate No BE-2-21 issued at 2007-04-13) and conform to the ethical guidelines of the 2000 Declaration of Helsinki. Written informed consent was obtained from each study patient.

\section{Materials and methods Study population}

The study was a cross-sectional investigation of 1,027 consecutive medically stable CAD patients attending the Clinic of Cardiovascular Rehabilitation, from October 2007 until December 2014 for routine cardiac rehabilitation program.
Criteria for inclusion to the study were as follows: patients with CAD, men and women, 18 years and older, consecutively referred to the rehabilitation clinic within 2 weeks after treatment for acute coronary syndromes (ACS), no current drug or mechanical treatment for SA. All patients were receiving standard treatment for secondary prevention of CAD and heart failure according to existing guidelines.

One hundred and thirty-seven (13.3\%) of the patients were excluded from the study for meeting the criteria of being $>80$ years and having cognitive disorientation and communicative disabilities, having other severe diseases or not consent to participate in the program. In total, 775 (75.4\%) participants had successful PSG, of which 772 also had PSG data in conjunction with echocardiographic (left ventricular ejection fraction, LVEF) and Epworth sleepiness scale (ESS) data (the other 115 with successful echocardiography data either elected not to undergo PSG or were ineligible due to medical reasons). A few PSG were technically inadequate $(n=3)$. Although the inclusion rate for eligible patients for study analysis was 772 (75\%), the inclusion design was consecutive, and there were no significant differences in baseline characteristics with regard to comorbidities.

\section{Patient assessment}

All patients were evaluated for demographic characteristics (age, gender), CAD risk factors - smoking, arterial hypertension, body mass index (BMI), diabetes mellitus and clinical characteristics, including New York Heart Association (NYHA) functional class and use of medications. Hypertension was defined as blood pressure $>140 / 90 \mathrm{mmHg}$ measuring BP using sphygmomanometer or if the subject was receiving antihypertensive medications. Current smoking was defined as self-report of active smoking within the last year before the examination.

\section{Epworth sleepiness scale}

ESS was used for evaluation of the subjective excessive daytime sleepiness (EDS). Briefly, the patient rated the probability of dozing (0-3) in 8 different situations. No specific time frame was specified. The ESS score represented the sum of individual items, and ranged from 0 to 24 . A score $\geq 10$ was considered as positive for the presence of EDS. ${ }^{13}$

\section{Anthropometry}

Patients were divided into BMI categories based on World Health Organization (WHO)/National Institutes of Health guidelines: underweight (BMI $<18.5 \mathrm{~kg} / \mathrm{m}^{2}$ [excluded from study cohort]), healthy weight (BMI $18.5-24.9 \mathrm{~kg} / \mathrm{m}^{2}$ ), 
overweight (BMI 25-29.9 $\mathrm{kg} / \mathrm{m}^{2}$ ), and obese (BMI $\geq 30.0 \mathrm{~kg} / \mathrm{m}^{2}$ ). We calculated the waist-to-hip ratio as the ratio of the circumference of the waist to that of the hip and abdominal obesity (WHR $\geq 1.0$ ), as recommended by WHO. ${ }^{14}$

\section{Echocardiography}

Echocardiographic evaluation of the patients was blinded according to the presence and severity of sleep apnea. LV systolic function was assessed by LVEF using the modified biplane Simpson's method with apical 2- and 4-chamber views. It was defined as reduced LVEF while LVEF $<45 \%$.

\section{Polysomnography, definition of SA}

Overnight fully attended PSG monitoring was performed with the "Alice 4" PSG System (Respironics Inc., Marietta, GA, USA) in the sleep laboratory using standard recording techniques according to American Academy of Sleep Medicine (AASM) and precise protocol of PSG monitoring. ${ }^{15}$ Intake of sedative medication was not allowed within $48 \mathrm{~h}$ of the investigation. Airflow was monitored using a thermistor placed at the nose and mouth, and arterial oxygen saturation $\left(\mathrm{SaO}_{2}\right)$ was recorded continuously with a pulse oximeter. Apnea was defined as the disappearance of airflow for over $10 \mathrm{~s}$; hypopnea was defined as a $\geq 50 \%$ decrease in airflow lasting for $>10 \mathrm{~s}$ associated with arousal or a $\geq 3 \%$ decrease in $\mathrm{SaO}_{2}$ from the baseline level. All forms of SDB were noted, and recorded as obstructive, central or mixed where combination was seen. The mechanisms responsible for central sleep apnea (CSA) and obstructive sleep apnea (OSA) may overlap, and patients with central apneas often also have obstructive events. An obstructive apnea is a $\geq 10$-s pause in respiration associated with ongoing ventilatory effort. A central apnea is a $\geq 10$-s pause in ventilation with no associated respiratory effort. ${ }^{12,15} \mathrm{CSA}$ is particularly common among patients who have heart failure or have had a stroke. ${ }^{12}$ The most common type of SA is OSA, and much of the pathophysiologic understanding of SA relies on studies of OSA. ${ }^{12}$ In our study, the influence of central and obstructive events was not separately analyzed.

The apnea-hypopnea index (AHI) is the most commonly used characteristic of SA. Although SA syndrome includes both, a PSG abnormality and symptoms, its severity is often defined by AHI alone. The AHI was calculated as the total number of apnea and hypopnea episodes per hour of sleep. According to the AASM criteria, ${ }^{15}$ SA was defined with usual clinical AHI thresholds: no SDB, $<5$ events/h; mild, $\geq 5$ to $<15$ events/h; moderate, $\geq 15$ to $<30$ events $/ \mathrm{h}$; and severe, $\geq 30$ events $/ \mathrm{h}$. We defined EDS as an Epworth score $>10$ (maximum score 24). ${ }^{13}$ To improve comparability with earlier studies on SA, 2 different cut-off levels of AHI were used for adapting a definition of mild-to-severe (AHI $\geq 5$ ) or moderate-to-severe $(\mathrm{AHI} \geq 15) \mathrm{SA}$.

\section{Statistical analysis}

Quantitative variables are expressed as means \pm SD or medians (interquartile ranges [IQRs]) or in percentages, when appropriate. The Student's $t$-test for independent samples and the Mann-Whitney $U$-test were used to compare continuous variables when appropriate. The chi-squared test was used for categorical variables. We used logistic regression models to assess the association between various demographic and clinical variables and both mild-to-severe $\mathrm{SA}(\mathrm{AHI} \geq 5 / \mathrm{h})$ and moderate-to-severe $S A(A H I \geq 15 / h)$. The models included the same set of potential clinical predictors of SA: age (including cut-off, $\geq 60$ years, which was roughly the median age of the total participants; age groups of the $<50,50-70$, and $>70$-year or of the $<40,40-60$-year, and $>60$-year), sex, BMI, LV systolic dysfunction (LVEF $\leq 45 \%$ ), NYHA functional class, history of hypertension, current diabetes, waist circumference, waist-to-hip ratio, abdominal obesity (WHR $\geq 1.0$, or not), smoking status (current smoker), current use of medications (antihypertensive, antiagregants, amiodarone). Because daytime sleepiness is common in patients with SA, this factor was taken into account as a potential confounding factor. The cut-off used for ESS ( $\geq 6)$ was obtained using receiver operating characteristic curve analysis as the best values for sensitivity and specificity. We hypothesized that a BMI was a risk factor for $\mathrm{SA}$ in males not in females. For that purpose we tested by interactions between BMI and gender by incorporating 2-way interaction term $(\mathrm{BMI} \times \operatorname{sex})$ into a logistic regression model with SA as the dependent variable. Because there was evidence of effect modification by sex, separate models were constructed for men and women.

Variables with a $P$-value $<0.1$ upon univariate analysis as well as the nonsignificant variables with supposed clinical relevance, were included into a multivariate binary logistic regression. Data were analyzed with SPSS 17.0 statistical software (SPSS Inc., Chicago, IL, USA). A $P$-value $\leq 0.05$ was considered statistically significant.

\section{Results \\ Distribution of clinical features from the data set}

Among a total of 772 patients with CAD, 230 (29.8\%) patients had stable angina, 729 (94.4\%) patients after acute MI, and 91 (11.7\%) patients had previous MI. The largest proportion of patients was in NYHA Class II ( $77 \%$ of total). 
Among those included in the analysis, the median age was 58 years (ranged from 32 to 81), 186 (24\%) were women (Table 1$)$. The female patients were older ( $61 \pm 8$ vs $56 \pm 9$ years, $P<0.001)$ than the male patients.

The median value of the AHI in the sample was 3.4 and the IQR (25th-75th percentile) was $1-9$. Figure 1 shows the prevalence of SA according to clinically defined categories (mild, moderate and severe) and age.

The prevalence of mild-to-severe SA was noted $28 \%$ $(52 / 186)$ in women, $42 \%(248 / 586)$ in men $(P<0.001)$ and $39 \%$ (300/772) overall, whereas an AHI $\geq 15 / \mathrm{h}$ (moderateto-severe SA) was noted $6.5 \%(12 / 186)$ in women, $16.4 \%$ $(96 / 586)$ in men $(P<0.001)$ and 14\% $(108 / 772)$ overall.

The prevalence of mild-to-severe sleep apnea $(\mathrm{AHI} \geq 5 / \mathrm{h})$ increased with age and was $26.3 \%, 41.5 \%$ and $56.9 \%$ for the $<50,50-70$ and $>70$-year age groups, respectively. Applying a cut-off level of an AHI $\geq 15 / \mathrm{h}$, the SA prevalence was stable in patients $>50$ years old: $9.1 \%, 15.5 \%$ and $15.7 \%$ of the $<50,50-70$ and $>70$-year age groups, respectively (data not shown).

As illustrated in Figure 2, when adding SA to the traditionally recognized risk factors for CAD, hypertension (83\%) and obesity (47\%) were most frequently followed in order of frequency by mild-to-severe SA (39\%), diabetes mellitus (21\%), current smoking (12.6\%) and pulmonary disease $(6.2 \%)$. There were $17 \%$ of CAD patients reported EDS, and only $57 / 772$ (7.4\%) were "sleepy SA" patients (SA + EDS).

\section{Demographic and clinical characteristics of the patients with and without SA according to cut-off $\mathrm{AHI} \geq 5 / \mathrm{h}$}

Table 1 summarizes the patient demographics and clinical characteristics of the total sample and divides the patients according to the absence or presence of SA according to

Table I Demographic and clinical characteristics of the total sample of patients with CAD and the patients with and without mild-tosevere SA

\begin{tabular}{|c|c|c|c|c|}
\hline Characteristic & $\begin{array}{l}\text { Total sample } \\
\mathbf{N}=772\end{array}$ & $\begin{array}{l}\text { Non-SA AHI: }<5 \\
n=472\end{array}$ & $\begin{array}{l}\text { Mild-to-severe SA } \\
\text { AHI: } \geq \mathbf{5} \\
\mathrm{n}=\mathbf{3 0 0}\end{array}$ & $P$-value ${ }^{a}$ \\
\hline Age, mean (SD), years & $57(9)$ & $56(9)$ & $59(9)$ & $<0.001$ \\
\hline Median (IQR) & $58(51-64)$ & $57(49-63)$ & $60(53-66)$ & $<0.00$ I \\
\hline Male gender, n (\%) & $586(76)$ & $338(72)$ & $248(83)$ & 0.001 \\
\hline Female gender, $\mathrm{n}(\%)$ & $186(24)$ & 134 (28) & $52(17)$ & \\
\hline Age $>60$ years, $n(\%)$ & $344(47)$ & $191(40)$ & $153(50)$ & $\chi^{2}=8.2, P=0.004$ \\
\hline Waist circumference, mean (SD) cm & $101.1(12.0)$ & $99.0(11.5)$ & $104.3(12.1)$ & $<0.001$ \\
\hline WHR & $0.97(0.07)$ & $0.95(0.07)$ & $0.99(0.07)$ & $<0.001$ \\
\hline Abdominal obesity (WHR $\geq \mathrm{I}), \mathrm{n}(\%)$ & $278(36)$ & $144(30.5)$ & $134(44.7)$ & $\chi^{2}=15.9, \mathbf{P}<\mathbf{0 . 0 0 1}$ \\
\hline Body mass index, mean (SD), $\mathrm{kg} / \mathrm{m}^{2}$ & $30.0(4.8)$ & $29.4(4.6)$ & $31.0(5.0)$ & $<0.001$ \\
\hline Body mass index, $n(\%)$ & & & & $\chi^{2}=11.8, P=0.003$ \\
\hline Normal $\left(<25 \mathrm{~kg} / \mathrm{m}^{2}\right)$ & $104(13.5)$ & $78(16.5)$ & $26(8.7)$ & \\
\hline Overweight $\left(25-24.9 \mathrm{~kg} / \mathrm{m}^{2}\right)$ & $305(39.5)$ & $189(40.0)$ & $116(38.7)$ & \\
\hline Obese $\left(\geq 30 \mathrm{~kg} / \mathrm{m}^{2}\right)$ & $363(47.0)$ & $205(43.4)$ & $158(52.7)$ & \\
\hline CAD & & & & $\chi^{2}=3.8, P=0.43$ \\
\hline Stable angina pectoris & $230(29.8)$ & I 40 (29.7) & $90(30.0)$ & \\
\hline First myocardial infarction & $729(94.4)$ & $278(58.8)$ & $173(57.7)$ & \\
\hline Previous myocardial infarction & $91(11.7)$ & $54($ (I I.5) & $37(12.3)$ & \\
\hline NYHA class, n (\%) & & & & $\chi^{2}=4.8, P=0.09$ \\
\hline I & $65(8.4)$ & $48(10.2)$ & $17(5.7)$ & \\
\hline II & $598(77.5)$ & $359(76.4)$ & $239(79.9)$ & \\
\hline III & $106(13.7)$ & $63(13.4)$ & $43(14.4)$ & \\
\hline LVEF, mean (SD) \% & $5 \mathrm{I} .4(8.5)$ & $52.1(8.4)$ & $50.4(8.7)$ & 0.011 \\
\hline LVEF $\leq 45 \%, n(\%)$ & $175(22.7)$ & $95(22.4$ & $80(26.7)$ & $\chi^{2}=4.4, P=0.034$ \\
\hline Hypertension, n (\%) & $641(83.0)$ & $369(78.2)$ & $272(90.7)$ & $\chi^{2}=20, P<0.001$ \\
\hline Diabetes mellitus, n (\%) & $165(21.4)$ & $102(21.6)$ & $63(21.0)$ & $\chi^{2}=0.04, P=0.84$ \\
\hline History of smoking, n (\%) & $97(12.6)$ & $67(14.3)$ & $30(10.0)$ & $\chi^{2}=2.9, P=0.08$ \\
\hline \multicolumn{5}{|l|}{ ESS score } \\
\hline Mean (SD) & $6.3(3.5)$ & $6.0(3.5)$ & $6.7(3.5)$ & 0.008 \\
\hline Median (IQR) & $6(4-9)$ & $6(3-8)$ & $6(4-9)$ & 0.006 \\
\hline$E S S \geq 10, n(\%)$ & $13 \mid(17)$ & $74(15.7)$ & $57(19.0)$ & $\chi^{2}=1.4, P=0.14$ \\
\hline $\mathrm{ESS} \geq 6, \mathrm{n}(\%)$ & $417(54)$ & $240(50.8)$ & $177(59.4)$ & $\chi^{2}=5.3, \boldsymbol{P}=\mathbf{0 . 0} \mathbf{1 2}$ \\
\hline
\end{tabular}

Notes: ${ }^{a}$ Comparison between non-SA $(\mathrm{AHI}<5)$ and mild-to-severe $\mathrm{SA}(\mathrm{AHI} \geq 5)$; bold figures indicate significant difference.

Abbreviations: AHI, apnea-hypopnea index; CAD, coronary artery disease; ESS, Epworth sleepiness scale; IQR, interquartile range; LVEF, left ventricular ejection fraction; NYHA, New York Heart Association; SA, sleep apnea; SD, standard derivation; WHR, waist-to-hip ratio. 


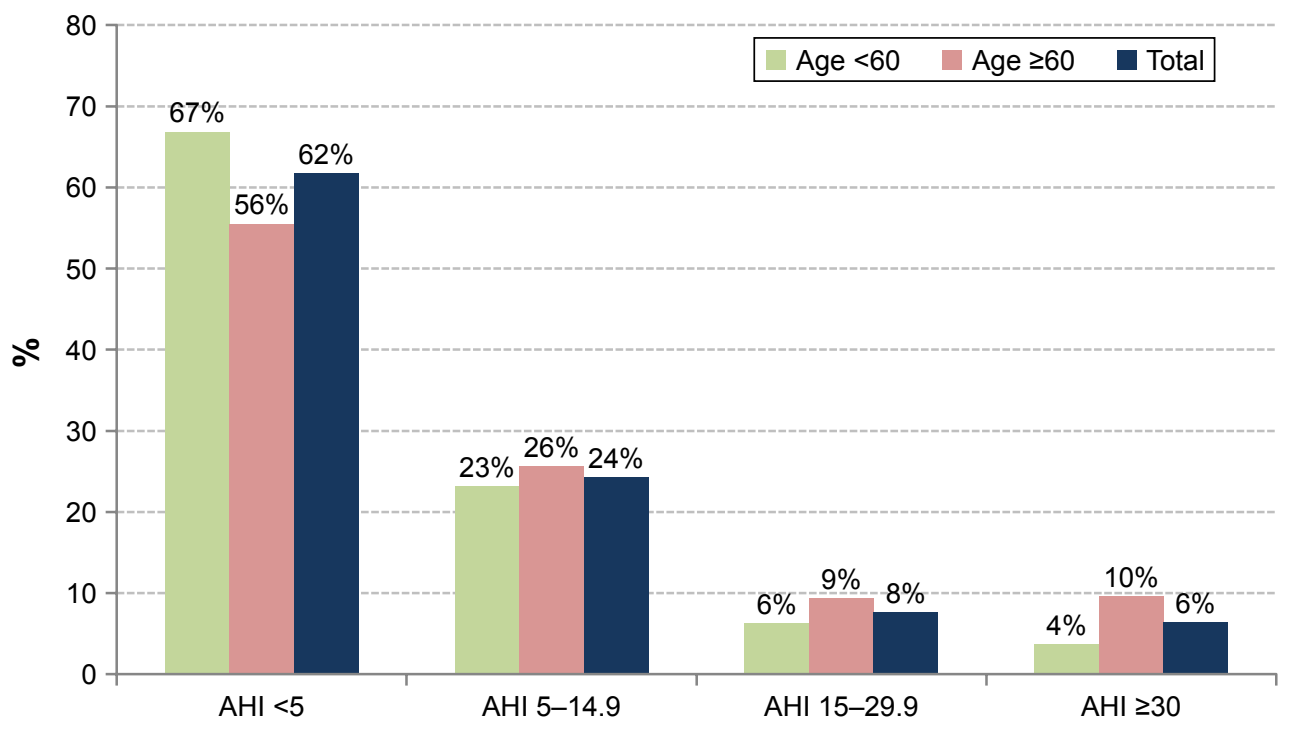

Figure I The distribution of CAD patients according to SA severity by age.

Abbreviations: AHI, apnea-hyponea index; CAD, coronary artery disease; SA, sleep apnea.

$\mathrm{AHI} \geq 5 / \mathrm{h}$. There were significant differences in age, sex, BMI, waist-to-hip ratio in the non-SA and SA groups, but the prevalence of NYHA class, history of diabetes mellitus and smoking were similar. There were no statistical differences after a comparison of the traditionally tested CV risk factors with the clinical manifestation of CAD, such as stable angina and MI ( $\chi^{2}$ test $P=0.43$ ). The $\mathrm{CV}$ risk indicators such as obesity and hypertension were more prevalent among patients with SA compared with patients without SA (53\% vs $43 \%$ and $91 \%$ vs $78 \%$, respectively; both $P<0.01$ ) (Table 1 ).

There was greater use of antihypertensive $(P=0.012)$, antiagregants $(P=0.003)$ and amiodarone $(P=0.030)$ in the SA than non-SA groups.

The SA group also had higher scores $(P=0.008)$ on the ESS; however, a percentage of EDS (ESS $\geq 10$ ) was similar in patients with and without SA (16\% and 19\%, respectively; $P=0.14)$. However, the mean ESS score was within the normal range in both groups. The EDS of the CAD patients included $89 / 428(20.8 \%)$ among those aged $<60$ and $42 / 344(12.2 \%)$ among aged $\geq 60(P=0.002)$. These data could be interpreted as support for the notion that older CAD patients are less sleepy than younger patients. However, the frequency of EDS among the individuals diagnosed with SA (AHI $\geq 5)$ in those age groups was similar $(21.8 \%$ and $16.3 \%, P=0.231)$.

Non-obese individuals (BMI $<30 \mathrm{~kg} / \mathrm{m}^{2}$ ) accounted for $47.7 \%$ (143/300) of all diagnoses of SA and $29.3 \%$ $(42 / 143)$ from those diagnosed with moderate-to-severe apnea (AHI $\geq 15$ ).

We also estimated that $8.4 \%$ of men and $4.3 \%$ of women had an $\mathrm{AHI} \geq 5$ plus symptoms of $\mathrm{EDS}(\mathrm{ESS} \geq 10)(P=0.065)$. Between "sleepy" (because of daytime sleepiness symptoms) and "non-sleepy" SA patients, there were no differences by age and gender, and differences in the prevalence of

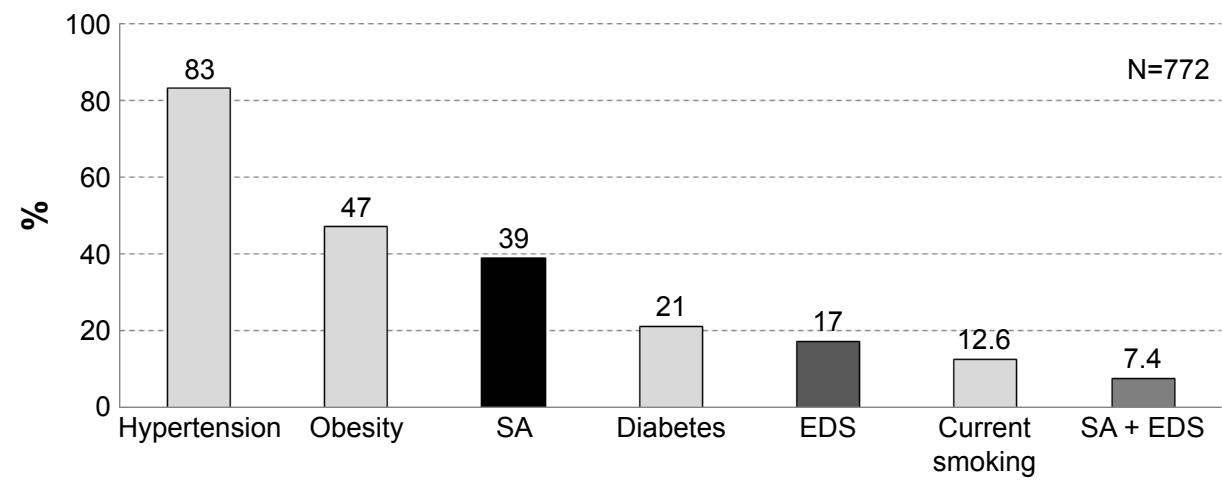

Figure 2 The distribution of SA and the traditionally recognized risk factors for CAD within study sample.

Notes: Obesity, body mass index $\geq 30 \mathrm{~kg} / \mathrm{m}^{2}$; EDS = ESS $>10 ; \mathrm{SA}=\mathrm{AHI} \geq 5$.

Abbreviations: AHI, apnea-hyponea index; CAD, coronary artery disease; EDS, excessive daytime sleepiness; ESS, Epworth sleepiness scale; SA, sleep apnea. 
Table 2 Univariate predictors of SA according to different cutoff of AHI in CAD patients

\begin{tabular}{|c|c|c|c|c|}
\hline \multirow[t]{3}{*}{ Variables } & Mild-to-severe SA & \multirow[t]{3}{*}{$P$-value } & Moderate-to-severe SA & \multirow[t]{3}{*}{$P$-value } \\
\hline & \multirow{2}{*}{$\begin{array}{l}\mathrm{AHI} \geq 5 \\
\text { OR }(95 \% \mathrm{CI})\end{array}$} & & \multirow{2}{*}{$\frac{\mathrm{AHI} \geq \mathrm{I5}}{\mathrm{OR}(95 \% \mathrm{CI})}$} & \\
\hline & & & & \\
\hline Age (per I0-year increment) & $1.45(1.23-1.72)$ & $<0.001$ & $1.49(1.18-1.88)$ & 0.001 \\
\hline Age $>60$ years & $1.53(1.14-2.05)$ & 0.004 & $2.09(1.38-3.16)$ & 0.001 \\
\hline Gender (men vs women) & $1.89(|.32-2.7|)$ & 0.001 & $2.84(\mid .52-5.31)$ & 0.001 \\
\hline \multicolumn{5}{|l|}{ BMI $\left(\mathrm{kg} / \mathrm{m}^{2}\right)$} \\
\hline $25-30$ (vs $<25)$ & $1.84(1.12-3.04)$ & 0.017 & $1.79(0.77-4.18)$ & 0.174 \\
\hline$>30(v s<25)$ & $2.3 I(I .4 I-3.77)$ & 0.001 & $3.08(1.37-6.94)$ & 0.007 \\
\hline Waist circumference (per I cm increment) & $1.04(1.02-1.05)$ & $<0.001$ & $1.04(1.03-1.06)$ & $<0.001$ \\
\hline Abdominal obesity $(\mathrm{WHR} \geq \mathrm{I})$ & $1.84(1.36-2.48)$ & $<0.001$ & $2.24(1.49-3.38)$ & $<0.001$ \\
\hline Current smoking & $0.67(0.42-1.06)$ & 0.087 & $0.67(0.34-1.34)$ & 0.260 \\
\hline ESS (per I score increment) & $1.06(1.01-1.10)$ & 0.009 & $\mathrm{I} .05(0.99-1 . \mathrm{II})$ & 0.123 \\
\hline ESS $(\geq 10$ vs $<10)$ & $1.26(0.86-1.84)$ & 0.231 & $\mathrm{I} .39(0.84-2.3 \mathrm{I})$ & 0.198 \\
\hline ESS $(\geq 6$ vs $<6)$ & I.4I (I.06-I.89) & 0.021 & $1.31(0.86-1.98)$ & 0.207 \\
\hline Hypertension & $2.7 I(1.73-4.24)$ & $<0.001$ & $2.18(I .|I-4.3|)$ & 0.024 \\
\hline Diabetes mellitus & $0.96(0.67-1.37)$ & 0.840 & $1.06(0.64-1.73)$ & 0.816 \\
\hline LVEF $\leq 45 \%$ & $1.44(1.02-2.02)$ & 0.035 & $1.09(0.68-1.76)$ & 0.707 \\
\hline Antihypertensive medication & $2.04(1.19-3.49)$ & 0.009 & $1.78(0.93-3.44)$ & 0.081 \\
\hline Antiagregants & $3.28(1.47-7.29)$ & 0.004 & $1.69(0.58-4.86)$ & 0.329 \\
\hline Amiodarone & $2.54(1.09-5.91)$ & 0.030 & $1.28(0.42-3.86)$ & 0.662 \\
\hline
\end{tabular}

Abbreviations: AHI, apnea-hypopnea index; BMI, body-mass index; CAD, coronary artery disease; Cl, confidence interval; ESS, Epworth sleepiness scale; LVEF, left ventricular ejection fraction; OR, odds ratio; SA, sleep apnea; WHR, waist-to-hip ratio.

comorbidities, except for diabetes mellitus, which was more common in sleepy than in non-sleepy SA patients $(31.6 \% \mathrm{vs}$ $18.5 \% ; P=0.029$ ) (data not shown).

\section{Predictors of SA according to different cut-off of AHI}

As shown in Table 2, univariate variables associated with mild-to-severe SA were age, male gender, BMI, obesity, ESS score (but not categorical ESS $\geq 10$ ), hypertension whereas current smoking and diabetes mellitus were inversely and not significantly correlated with SA. The OR was unaffected by AHI severity threshold (5 or 15 ) for age (continuous), waist, abdominal obesity, hypertension. The prevalence of SA increases with age, patients $\geq 60$ years had 1.5 times the risk of mild-to-severe SA and 2 times the risk of moderateto-severe SA compared with those in middle age.

\section{Assumed models for multivariate logistic regression}

A multivariate logistic regression analysis was performed to determine the independent predictors of SA (according to AHI $\geq 5$ or $\geq 15 / h$ ). The data listed in Table 3 show that the presence of mild-to-severe SA (AHI $\geq 5 / \mathrm{h}$ ) was associated with an increased age, male gender, hypertension, obesity $\left(\mathrm{BMI}>30 \mathrm{~kg} / \mathrm{m}^{2}\right)$, daytime sleepiness $(\mathrm{ESS} \geq 6)$ on the ESS and LV systolic dysfunction ( $\mathrm{LVEF} \leq 45 \%$ ). Hypertensive patients had a 2.4 -fold $(P=0.001)$ increase in the probability of mild-to-severe SA compared with patients without hypertension. BMI better predicts SA rather than waist circumference or abdominal obesity ( $\mathrm{WRH} \geq 1)$.

Prevalence of hypertension among those without and with moderate-to-severe SA was 81.8\% (543/664) and 90.7\% (98/108), respectively, $P=0.021$. However, on multiple logistic regression analysis, male gender, only age from 50 to 70 years and, mainly, the presence of obesity but not hypertension were independent predictors of moderate-to-severe $\mathrm{SA}(\mathrm{AHI} \geq 15 / \mathrm{h})$ in stable CAD patients (Table 4$)$.

Table 3 Independent variables associated with mild-to-severe SA $(\mathrm{AHI} \geq 5 / \mathrm{h})$ on multiple logistic regression analysis

\begin{tabular}{|c|c|c|}
\hline Variables & OR $(95 \% \mathrm{Cl})$ & $P$-value \\
\hline \multicolumn{3}{|l|}{ Age (years) } \\
\hline $50-70$ (vs < $<0$ ) & $2.07(1.40-3.07)$ & $<0.001$ \\
\hline$>70(v s<50)$ & 5.01 (2.52-9.97) & $<0.00$ I \\
\hline Gender (men vs women) & $2.25(1.52-3.34)$ & $<0.00 \mathrm{I}$ \\
\hline Hypertension & $2.39(1.48-3.85)$ & $<0.001$ \\
\hline \multicolumn{3}{|l|}{ BMI $\left(\mathrm{kg} / \mathrm{m}^{2}\right)$} \\
\hline $25-30($ vs $<25)$ & $1.57(0.92-2.68)$ & 0.097 \\
\hline$>30($ vs $<25)$ & $1.99(1.17-3.39)$ & 0.011 \\
\hline$E S S \geq 6$ & $1.43(1.04-1.96)$ & 0.027 \\
\hline LVEF $\leq 45 \%$ & $1.45(1.01-2.10)$ & 0.046 \\
\hline Antihypertensive medication & $2.06(1.17-3.63)$ & 0.013 \\
\hline Antiagregants & $2.81(1.23-6.40)$ & 0.014 \\
\hline
\end{tabular}

Abbreviations: $\mathrm{AHI}$, apnea-hypopnea index; $\mathrm{BMI}$, body mass index; $\mathrm{Cl}$, confidence interval; ESS, Epworth sleepiness scale; LVEF, left ventricular ejection fraction; OR, odds ratio; SA, sleep apnea. 
Table 4 Independent variables associated with moderate-tosevere $\mathrm{SA}(\mathrm{AHI} \geq \mathrm{I5} / \mathrm{h})$ on multiple logistic regression analysis

\begin{tabular}{|c|c|c|}
\hline Variables & OR $(95 \% \mathrm{CI})$ & $P$-value \\
\hline Gender (men vs women) & $3.48(1.84-6.59)$ & $<0.001$ \\
\hline \multicolumn{3}{|l|}{ Age (years) } \\
\hline $50-70(v s<50)$ & $1.98(1.13-3.47)$ & 0.017 \\
\hline$>70(v s<50)$ & $2.52(0.99-6.38)$ & 0.051 \\
\hline \multicolumn{3}{|l|}{ BMI $\left(\mathrm{kg} / \mathrm{m}^{2}\right)$} \\
\hline $25-30($ vs $<25)$ & $1.77(0.75-4.15)$ & 0.186 \\
\hline$>30(v s<25)$ & $3.41(1.50-7.78)$ & 0.003 \\
\hline
\end{tabular}

Notes: Bold figures indicate significant difference.

Abbreviations: $\mathrm{BMI}$, body mass index; $\mathrm{Cl}$, confidence interval; OR, odds ratio; SA, sleep apnea.

\section{Gender differences}

In addition, we tested by interactions between BMI and gender by incorporating multiplicative interaction terms $(\mathrm{BMI} \times \operatorname{sex})$ into the multivariate logistic regression model. When men and women were included in a single model to formally test for interaction between gender $(1=$ men; $0=$ women) and BMI, the interaction term was statistically significant $\left(\mathrm{OR}_{\mathrm{BMI} \times \mathrm{sex}}=1.03(1.02-1.04) ; P<0.001\right)$.

Overall AHI expressed as median (25th-75th percentile) was $3.9(1-10)$ and $2.3(0.9-5.5)$ events/ $h$ in men and women, respectively $(P<0.001)$. As shown in Table 5 , patients with SA of either sex tended to be older and had frequent hypertension when compared with their non-SA counterparts. The proportion of males with obesity was significantly higher in SA patients than the non-SA patients (Table 2). This difference was not seen in the females.

Sex-specific prediction was formulated to predict $\mathrm{AHI} \geq 5 / \mathrm{h}$ risk according to age, BMI, hypertension and also included other clinical predictors of SA are listed in Table 5 . We divided women into 2 age categories ( $\leq 60$ and $>60$ years) based on previous data in the literature suggesting that the risk of SA increases during postmenopausal years and men into 3 age groups $(<40 ; 40-60 ;>60$ years) based on previous data in the literature (Table 6). ${ }^{16}$

For men, age $>60$ years and BMI $\geq 30 \mathrm{~kg} / \mathrm{m}^{2}$ were the risk factors for SA (AHI $\geq 5$ ). However, for women, age $>60$ years but not obesity was significantly and independently related to SA. For both males and females, hypertension was the dominant risk factor for mild-to-severe SA and SA did not manifest with EDS. In addition, for women, frequent arousal can lead to the development daytime sleepiness; ESS scores were associated with mild-to-severe SA.

\section{Discussion \\ Summary of findings}

Overall, in this study, we found AHI within a range of values that is considered normal or only mildly elevated. The median value of the AHI in the sample was 3.4 (IQR 1-9); the mean ESS score was within the normal range. These patients did not show typical symptoms such as sleepiness and the risk-related cut-off score for excessive daily sleepiness was lower than the official for ESS. Older stable CAD patients were less "sleepy" than younger patients. Over one-third of patients had unrecognized SA (AHI $\geq 5$ events per hour), which was not higher than other known risk indicators for CAD such as hypertension and obesity (in this sample). The relative absence of association between SA and diabetes in our study could be explained by relatively low prevalence of

Table 5 Demographic and clinical characteristics of the patients with and without SA by gender

\begin{tabular}{|c|c|c|c|c|}
\hline \multirow[t]{2}{*}{ Characteristic } & \multicolumn{2}{|l|}{ Males $^{a}$} & \multicolumn{2}{|l|}{ Females $^{a}$} \\
\hline & $\begin{array}{l}\text { Non-SA AHI: }<5 \\
n=338\end{array}$ & $\begin{array}{l}\text { SA AHI: } \geq 5 \\
n=248\end{array}$ & $\begin{array}{l}\text { Non-SA AHI: }<5 \\
n=134\end{array}$ & $\begin{array}{l}\text { SA AHI: } \geq 5 \\
n=52\end{array}$ \\
\hline Age, mean (SD), years & $54.8(9.1)$ & $58.6(8.8)^{* * *}$ & $60.1(7.8)$ & $63(6.8)^{*}$ \\
\hline Age $>60$ years, $n(\%)$ & II5 (34) & II $5(46.4)^{* * *}$ & $76(56.7)$ & $38(73.1)^{*}$ \\
\hline Abdominal obesity (WHR $\geq 1)$, n (\%) & 121 (35.8) & $125(50.4)^{* * *}$ & $23(17.2)$ & $9(17.3)$ \\
\hline Obesity (BMI $\geq 30$ kg/m²), n (\%) & $|3|(38.8)$ & $124(50.4)^{* *}$ & $73(54.5)$ & $33(63.5)$ \\
\hline NYHA class, n (\%) & \multicolumn{2}{|l|}{$P$ for trend $=0.034^{*}$} & \multicolumn{2}{|l|}{$P$ for trend $=0.442$} \\
\hline I & $44(13.1)$ & $16(6.5)$ & $4(3)$ & I (I.9) \\
\hline II & $254(75.6)$ & $202(81.8)$ & 105 (78.4) & 37 (7I.2) \\
\hline III & $38(11.3)$ & $29(11.7)$ & $25(18.7)$ & 14 (26.9) \\
\hline LVEF $\leq 45 \%, \mathrm{n}(\%)$ & $66(19.5)$ & $70(28.2)^{*}$ & $29(21.6)$ & $10(19.2)$ \\
\hline Hypertension, n (\%) & $258(76.3)$ & $222(89.5)^{* * *}$ & III (82.8) & $50(96.2)^{*}$ \\
\hline Diabetes mellitus, n (\%) & $66(19.5)$ & $50(20.2)$ & $36(26.9)$ & $13(25.0)$ \\
\hline ESS score, mean (SD) & $6.4(3.6)$ & $6.8(3.5)$ & $5.2(3.1)$ & $6.2(3.8)^{*}$ \\
\hline$E S S \geq 10, n(\%)$ & 65 (19.2) & $49(19.8)$ & $9(6.7)$ & $8(15.4)$ \\
\hline $\mathrm{ESS} \geq 6, \mathrm{n}(\%)$ & 184 (54.4) & 149 (60.6) & $56(4 I .8)$ & $28(53.8)$ \\
\hline
\end{tabular}

Notes: a Comparison between SA and non-SA. $* P<0.05 ; * * P<0.01 ; * * * P<0.001$.

Abbreviations: AHI, apnea-hypopnea index; ESS, Epworth sleepiness scale; LVEF, left ventricular ejection fraction; NYHA, New York Heart Association; SA, sleep apnea; SD, standard derivation; WHR, waist-to-hip ratio. 
Table 6 Independent variables associated with mild-to-severe sleep apnea $(A H I \geq 5)$ on multiple logistic regression analysis in patients with CAD by gender

\begin{tabular}{|c|c|c|}
\hline $\begin{array}{l}\text { Multivariate analysis } \\
\text { (method: forward } \\
\text { conditional) }\end{array}$ & OR $(95 \% \mathrm{Cl})$ & $P$-value \\
\hline \multicolumn{3}{|l|}{ Women, $n=186$} \\
\hline Hypertension & $5.19(1.15-23.3)$ & 0.032 \\
\hline ESS per I score increment & $1.12(1.01-1.24)$ & 0.030 \\
\hline Age $>60$ vs $\leq 60$ years & $2.08(1.01-4.30)$ & 0.046 \\
\hline \multicolumn{3}{|l|}{ Men, $n=586$} \\
\hline \multirow[t]{2}{*}{ Age (years) } & & $P$ for trend \\
\hline & & $<0.001$ \\
\hline$(40-60)$ vs $<40$ & $2.60(0.83-8.09)$ & 0.099 \\
\hline$>60$ vs $<40$ & $5.10(1.6 I-16.12)$ & 0.005 \\
\hline $\mathrm{BMI} \geq 30 \mathrm{~kg} / \mathrm{m}^{2}$ & $1.72(1.15-2.55)$ & 0.008 \\
\hline Hypertension & $2.32(1.40-3.84)$ & 0.001 \\
\hline Antihypertensive & $2.05(1.01-4.14)$ & 0.045 \\
\hline LVEF $\leq 45 \%$ & $1.73(1.16-2.60)$ & 0.008 \\
\hline
\end{tabular}

Abbreviations: BMI, body mass index; CAD, coronary artery disease; $\mathrm{Cl}$, confidence interval; ESS, Epworth sleepiness scale; LVEF, left ventricular ejection fraction; OR, odds ratio.

this CAD risk factor in our patient population, and the fact that this prevalence was similar in patients with $\mathrm{SA}(\mathrm{AHI} \geq 5)$ and non-SA (21\%). Obesity, hypertension, age and male gender were the best predictors of mild-to-severe SA, even in the absence of daytime sleepiness. While, male gender, only age from 50 to 70 years and, mainly, the presence of obesity but not hypertension were independent predictors of moderate-to-severe SA (AHI $\geq 15$ ). The most important findings were that risk factors for SA in women differed from those in men. An association between mild-to-severe SA and obesity was not evident in women. Additionally, daytime sleepiness was associated with mild-to-severe SA in women but not in men.

\section{Prevalence of SA}

Information regarding the prevalence of SA in CAD cohorts is unfortunately scarce. The data reported earlier show a wide range of prevalence rates for SA in CAD. In part, this is due to the use of different definitions of SDB and different cut-off values for AHI, which make comparing rates between studies difficult. Previous studies have shown a prevalence of SA as high as $30 \%-50 \%$ in patients with $\mathrm{CAD}^{2,17}$ In a review, including 11 small studies with a total number of $776 \mathrm{CAD}$ patients, the mean prevalence of SA (AHI >10) was reported to be $42 \%{ }^{18}$ Recently published data from the Reha-Sleep registry, investigating the prevalence of SDB in cardiac rehabilitation patients, reported that clinically significant SA (AHI $\geq 15 / h$ ) was documented in $33 \%$ of patients. ${ }^{19}$ Applying a cut-off level of an AHI of 15, the SA prevalence in our study was $14 \%$ (16.4\% in men, $6.5 \%$ in women). Our study, using a cross-sectional design, is fraught with problems of uncertainty, bias and confounding. There is some evidence suggesting that the prevalence and the severity of SA are modified along the CAD evolution. Moruzzi et al observed a significantly higher AHI in CAD patients immediately after an acute $\mathrm{MI}$ and after clinical stabilization of unstable angina pectoris compared with stable angina pectoris patients. ${ }^{20}$ For comparison, prevalence of SA in studies of patients with ACS was high from $54 \%$ to $66 \%{ }^{21-23}$ However, in the study conducted in Greece, this prevalence decreased 6 months after ACS and persisted in $21 \%$ of the patients, which indicated that this abnormality may be transient. ${ }^{22,24}$

A variable time gap existed between clinical assessment of patients and PSG, but it probably did not affect the association between severity of SDB and diabetes, hypertension, metabolic syndrome and depression, since these disorders are typically chronic conditions. ${ }^{25}$ Longitudinal cohort studies, which explicitly embody the dimension of time, can be quite informative despite their observational nature. The study of Peker et $\mathrm{al}^{5}$ demonstrated an increased incidence of CAD in middle-aged SA patients during a follow-up period of 7 years. Disregarding treatment, SA was associated with an almost 5-fold increase in risk of development of CAD independent of age, sex, hypertension, diabetes and current smoking. Regarding the low oxygen desaturation index at baseline in this study population, even mild SA seemed to have a substantial effect on CAD risk. ${ }^{5}$

The cross-sectional associations from the baseline examination of the community-based Sleep Heart Health Study cohort are compatible with effects of SDB on various manifestations of CVD within a range of AHI values that is considered normal or only mildly elevated. ${ }^{26}$ Analysis from this multicenter cohort study of the CV consequences of SDB showed that the median value of the AHI in the sample was 4.4 (IQR 1.3-11). ${ }^{26}$ If the observed associations are indeed causal, a modestly elevated risk coupled with a high prevalence of mild SDB might have considerable public health implications. In our cross-sectional study of documented stable CAD patients, it was found that AHI was within a similar range. AHI values of this magnitude are not uncommon in the general population but, for most individuals, remain unrecognized. ${ }^{27}$ These findings could indicate that the effect of SDB on CVD risk is fully realized at some level. ${ }^{26}$ Also is of interest in the concurrent presence of the commonality of $\mathrm{SA}, \mathrm{CV}$ disease and their common risk factors. 


\section{Clinical risk factors associated with SA Age}

Early studies suggested the interesting and clinically relevant possibility that SA may have more deleterious $\mathrm{CV}$ consequences in subjects $<50$ years of age..$^{28}$ Our data support the hypotheses that SA increases in prevalence to about age 55 years, after which it fails to increase or decrease, depending on the diagnostic criteria employed. Bixler et al reported an increase in SA after 65 years but the frequency of SA syndrome declined. ${ }^{29}$ In our study, the frequency of mildto-severe SA increases; however, prevalence of moderate-to severe SA (AHI $\geq 15$ events/h) was stable after the age of 50 years. Data from the community-based Sleep Heart Health Study have shown that disease prevalence increases steadily with age and reaches a plateau after the age of 60 years. ${ }^{30}$ Similar trends with increasing age have also been noted in other cohorts in whom the prevalence of moderate-to-severe OSA (AHI $\geq 15-20$ events/h) remains relatively constant after the sixth decade of life. ${ }^{31}$ Mechanisms proposed for the age-related increase in prevalence include increased deposition of fat in the parapharyngeal area, lengthening of the soft palate and changes in body structures surrounding the pharynx..$^{32,33}$ Thus, the epidemiologic finding of Bixler et al that SA is more severe in the young is consistent with these clinical data, which indicate that the clinical impact of apneic activity is weaker in the elderly. ${ }^{27}$

All of these data also tend to support the idea that the elderly population might be considered the "survivor" population. ${ }^{34}$ An alternative explanation for the increased prevalence of SA in older people is that the prevalence of comorbidities associated with SA is higher in older people, for example, chronic heart failure. ${ }^{35}$ In this late condition, complex bidirectional relationships occur, with OSA being a risk factor for heart failure while CSA mainly appears as a consequence of heart failure. ${ }^{35,36}$ Indeed, it is estimated that about $50 \%$ of heart failure patients will have sleep-related breathing disorders, ${ }^{35}$ but other disorders, such as diabetes and renal failure, also have high prevalence of SA and are increased in older people. ${ }^{37}$ However, it seems that this is mainly true before the age of 70 years. ${ }^{38}$ On the other hand, in older patients, the CV risk does not seem to increase compared with non-SA, at least for hypertension and CAD. ${ }^{36}$

\section{Hypertension}

Both SA and hypertension are common, and many individuals have both conditions. SA has been proposed as an independent risk factor for the development of essential hypertension because it can precede and predict the onset of hypertension. The association between SA and hypertension is gaining prominence. SA has been recognized as a cause for underdiagnosed hypertension. The Wisconsin Sleep Cohort Study noted a consistent SA-BP (blood pressure) dose-response relationship, even after controlling for age, sex, BMI and antihypertensive medications. ${ }^{4}$ Effects of SA on hypertension may be especially evident in middle-aged compared with older subjects, and SA may predominantly raise systolic BP. ${ }^{39}$ In another study, SA was found to be an independent predictor of uncontrolled hypertension in patients $<50$ years of age. ${ }^{40}$

In our study, hypertension cases had been accumulated over an extensive time period and the hypertension diagnosis was evidently well established. It is, therefore, apparent that a different subset of hypertension sufferers was addressed in the present study. We found that hypertension as predictors was for mild-to-severe, but not for moderate-to-severe SA. Controversial, in Glantz study, age, male sex, BMI and ESS score, but not comorbidities, were independent predictors of SA in revascularized CAD cohort. ${ }^{41}$ SA may represent a synergistic risk factor for hypertension development in certain subjects with, for example, comorbid obesity, a metabolic disease or certain coexisting traditional risk factors. ${ }^{18}$ Peppard et al found no evidence of a threshold of the AHI below which hypertension was not related to SDB. They reported that even persons with minimal SDB (as defined by an apnea-hypopnea index of 0.1-4.9 events per hour) had higher odds of hypertension than those with no episodes of SDB. If even those with minimal SDB are at higher risk for hypertension, then the proportion of cases of hypertension that are attributable to this factor may be substantial. ${ }^{4}$ The existing evidence encourages considering SA in the evaluation of all hypertensive patients. SA has been recognized as a cause for underdiagnosed hypertension.

\section{Body weight and gender}

The most important modifiable risk factor for SA is excess body weight. ${ }^{27}$ Apnea and obesity are both major health problems and physicians should view SA and obesity as independent clinical problems. A higher BMI is closely related to the incidence and severity of SA. However, we found that for men obesity was significantly related to mildto-severe SA, and for women, age $>60$ years but not obesity was related to mild-to-severe SA. Franklin et al reported that $39 \%$ of normal weighted women had SA but only $0.1 \%$ of them had severe SA ${ }^{42}$ Our finding supports previous reports 
from studies in heart failure patients referred for PSG. ${ }^{16}$ In the proper situation, apnea should be suspected in the nonobese individual. In our study, nonobese patients accounted for half of all diagnoses of mild-to-severe SA and 29\% from them were diagnosed with moderate-to-severe SA.

Although SA has a male predominance, recent data indicate that it is also a common disorder in females, especially after menopause. ${ }^{43}$ Hormonal influences are also likely to have an important role in pathogenesis of OSA, as disease prevalence is higher in post- versus pre-menopausal women. ${ }^{44}$ In general population samples, it has been shown that SA occurs more frequently than assumed in women. Most estimates of the male/female ratio in the general public range between $2: 1$ and $4: 1 .^{27,44}$ In our study, the male/female ratio for SA using criteria $\mathrm{AHI} \geq 5$ and $\mathrm{AHI} \geq 15$ was lower: 1.5:1 and 2.3:1, respectively. The prevalence of SDB has not been well studied in women, especially in terms of the effects of age, BMI and menopause. As a result of the association between SA and aging, women at postmenopausal age and men may have a similar prevalence of SA. It has been reported that women with $\mathrm{CAD}$ are older, have a higher burden of co-morbid illnesses and have lower referral/participation in cardiac rehabilitation programs compared with men. ${ }^{45}$ These findings underline the fact that conclusions based on research performed on men with $\mathrm{CAD}$ may not be valid for women and that more gender-related research is needed.

\section{Burden of undiagnosed SA}

Studies including patients with coronary disease have yielded conflicting data about the prognostic importance of disordered breathing. The mechanisms by which SA increases medical morbidity are complex and remain a focus of intense basic and human research. Lavie et al in a prospective study found that the apnea index was a predictor of excess mortality in the fourth and fifth decades but not in elderly men. ${ }^{28}$ Mooe et al hypothesized that a potential adverse effect of disordered breathing would be more obvious in patients with established vascular disease. The results of their study show that SDB in patients with CAD is associated with a 60\%-70\% increase in the risk of death and $\mathrm{CV}$ morbidity during long-term follow-up. Moreover, disordered breathing is an independent risk factor for stroke in patients with CAD. ${ }^{17,46}$

The usual indication to diagnose and treat SA is subjective sleepiness. In our study, many CAD patients with SA do not experience daytime sleepiness. It should be noted that, although patients with SA had a higher mean value of the ESS than non-SA patients, the mean ESS score was within the normal range in both groups. In the large mortality follow-up study, Lavie et al found that most patients are referred for SA diagnosis in their fifth decade of life when symptoms are severe enough to disrupt their daily lives. ${ }^{28} \mathrm{It}$ is evident that diagnosis and treatment will be too late for many of the patients who are at maximum risk. Therefore, diagnosis and treatment of SA should be done at the youngest possible age, which requires a more active approach toward diagnosis by sleep or other healthcare specialists. ${ }^{28}$ In our study, anthropometric obesity measurements (as waist and hip circumference) and the ESS alone were unreliable in predicting SA in stable CAD patients. BMI better predicted SA rather than waist circumference or abdominal obesity. The limitations of ESS are known in CV patients and the existence of patients with severe SA without excessive sleepiness is controversial. ${ }^{47,48}$ An independent association between $\mathrm{CV}$ morbidity and breathing disorders in sleep was reported even for patients with SA within the normal range of AHI (1-10 events/h). ${ }^{26}$ Although it is not feasible to refer all patients with CAD for a polysomnographic study in a sleep laboratory, some form of screening for SDB is needed. Exploring potential causes and improving recognition as well as SA treatment in cardiology might have benefits in the reduction of CV morbidity and mortality.

\section{Limitations and strengths of the study}

We acknowledge few limitations of this study. First, the cross-sectional design does not permit analysis of causal relationships. Unfortunately, the real duration of the SA was not known. A potential limitation is that our study was performed in a clinic-based sample. Second, in our study, the influence of central and obstructive events was not separately analyzed. The causative mechanisms of obstructive and central type SA differ, but the physiological and hence $\mathrm{CV}$ sequelae can be considered in unison. ${ }^{12,49}$ Because we reported prevalence for SA overall, but not for the subgroups of OSA and CSA, we cannot exclude the possibility that the risk factors identified relate only to one of these conditions, rather than both. Third, the study was not sex balanced; the female subjects were almost exclusively post-menopausal; and based on previous data in the literature, the risk of SA increases several years postmenopausally. ${ }^{50}$

The strengths of this study include relatively large sample size. First, by including a large sample of patients and numerous confounding covariates, our study has overcome many of the methodological limitations and provides strong support for an independent cross-sectional association with SA. Second, all of our subjects had comprehensive overnight standardized PSG data. 


\section{Conclusion}

SA is prevalent comorbidity in the stable CAD patients, especially in its asymptomatic mild form. Male gender, age, obesity, hypertension and LV dysfunction were clinical risk factors for the presence of SA. The most important findings were that risk factors for SA in women differed from those in men. An association between SA and obesity was not evident in women. We suggest that SA should be considered in the secondary prevention protocols for CAD.

\section{Author contributions}

AA: first author of this work participated in the polysomnographic measurement, involved in the early conception of the idea, proposal development data analysis, manuscript writing and submitting to the publishing journal. GV, JB: were the focal persons responsible for assessment of the clinical state of patients and participated in the study design, led the interpretation of research findings. NR: gave guidance on writing this paper and contributed to the statistical analysis. All authors contributed toward data analysis, drafting and revising the paper and agree to be accountable for all aspects of the work.

\section{Disclosure}

The authors report no conflicts of interest in this work.

\section{References}

1. De Torres-Alba F, Gemma D, Armada-Romero E, Rey-Blas JR, Lópezde-Sá E, López-Sendon JL. Obstructive sleep apnea and coronary artery disease: from pathophysiology to clinical implications. Pulm Med. 2013;2013:768064.

2. Konecny T, Kuniyoshi FH, Orban M, et al. Under-diagnosis of sleep apnea in patients after acute myocardial infarction. J Am Coll Cardiol. 2010;56(9):742-743.

3. Baguet JP, Barone-Rochette G, Tamisier R, et al. Mechanisms of cardiac dysfunction in obstructive sleep apnea. Nat Rev Cardiol. 2012; 9(12):679-688.

4. Peppard PE, Young T, Barnet JH, Palta M, Hagen EW, Hla KM. Increased prevalence of sleep-disordered breathing in adults. $\mathrm{Am} \mathrm{J}$ Epidemiol. 2013;177(9):1006-1014.

5. Peker Y, Carlson J, Hedner J. Increased incidence of coronary artery disease in sleep apnoea: a long-term follow-up. Eur Respir J. 2006;28(3):596-602.

6. Carpio C, Álvarez-Sala R, García-Río F. Epidemiological and pathogenic relationship between sleep apnea and ischemic heart disease. Pulm Med. 2013;2013:405827.

7. Punjabi NM. The epidemiology of adult obstructive sleep apnea. Proc Am Thorac Soc. 2008;5(2):136-143.

8. Skomro RP, Kryger MH. Clinical presentations of obstructive sleep apnea syndrome. Prog Cardiovasc Dis. 1999;41(5):331-340.

9. Leung RS, Bradley TD. Sleep apnea and cardiovascular disease. Am J Respir Crit Care Med. 2001;164(12):2147-2165.

10. Laaban JP, Pascal-Sebaoun S, Bloch E, Orvoen-Frija E, Oppert JM, Huchon $\mathrm{G}$. Left ventricular systolic dysfunction in patients with obstructive sleep apnea syndrome. Chest. 2002;122(4):1133-1138.
11. Fung JW, Li TS, Choy DK, et al. Severe obstructive sleep apnea is associated with left ventricular diastolic dysfunction. Chest. 2002;121(2): 422-429.

12. Somers VK, White DP, Amin R. Sleep apnea and cardiovascular disease: an American Heart Association/American College of Cardiology Foundation Scientific Statement From the American Heart Association Council for High Blood Pressure Research Professional Education Committee, Council on Clinical Cardiology, Stroke Council, and Council on Cardiovascular Nursing. Circulation. 2008;118:1080-1111.

13. Johns MW. Daytime sleepiness, snoring and obstructive sleep apnea: the Epworth Sleepiness Scale. Chest. 1993;103(1):30-36.

14. World Health Organization. Obesity: preventing and managing the global epidemic. Report of a WHO consultation on obesity. Geneva; 1997.

15. Iber C, Ancoli-Israel S, Chesson A, Quan SF. The AASM Manual for the Scoring of Sleep and Associated Events: Rules, Terminology and Technical Specifications. 1st ed. Westchester, IL: American Academy of Sleep Medicine; 2007.

16. Sin DD, Fitzgerald F, Parker JD, et al. Risk factors for central and obstructive sleep apnea in 450 men and women with congestive heart failure. Am J Respir Crit Care Med. 1999;160(4):1101-1106.

17. Mooe T, Franklin KA, Holmström K, Rabben T, Wiklund U. Sleepdisordered breathing and coronary artery disease, long-term prognosis. Am J Respir Crit Care Med. 2001;164(10):1910-1913.

18. Hedner J, Grote L, Bonsignore M, et al. The European Sleep Apnoea Database (ESADA): report from 22 European sleep laboratories. Eur Respir J. 2011;38(3):635-642.

19. Skobel E, Kamke W, Bonner G, et al. Risk factors for, and prevalence of, sleep apnoea in cardiac rehabilitation facilities in Germany: the Reha-Sleep registry. Eur J Prev Cardiol. 2015;22(7):820-830.

20. Moruzzi P, Sarzi-Braga S, Rossi M, Contini M. Sleep apnoea in ischaemic heart disease: differences between acute and chronic coronary syndromes. Heart. 1999;82(3):343-347.

21. BaHammam A, Al-Mobeireek A, Al-Nozha M, Al-Tahan A, Binsaeed A. Behaviour and timecourse of sleep disordered breathing in patients with acute coronary syndromes. Int J Clin Pract. 2005;59(8):874-880.

22. Mehra R, Principe-Rodriguez K, Kirchner HL, Strohl KP. Sleep apnea in acute coronary syndrome: high prevalence but low impact on 6-month outcome. Sleep Med. 2006;7(6):521-528.

23. Fox H, Purucker HC, Holzhacker I, et al. Prevalence of sleep-disordered breathing and patient characteristics in a coronary artery disease cohort undergoing cardiovascular rehabilitation. J Cardiopulm Rehabil Prev. 2016;36(6):421-429.

24. Bouloukaki I, Simantirakis E, Mermigis C, et al. Sleep-disordered breathing in patients with acute coronary syndrome. J Sleep Res. 2010; 19:296-297.

25. Heinzer R, Vat S, Marques-Vidal P, et al. Prevalence of sleep-disordered breathing in the general population: the HypnoLaus study. Lancet Respir Med. 2015;3(4):310-318.

26. Shahar E, Whitney CW, Redline S, et al. Sleep-disordered breathing and cardiovascular disease: cross-sectional results of the Sleep Heart Health Study. Am J Respir Crit Care Med. 2001;163(1):19-25.

27. Young T, Palta M, Dempsey J, Skatrud J, Weber S, Badr S. The occurrence of sleep-disordered breathing among middle-aged adults. $N$ Engl J Med. 1993;328(17):1230-1235.

28. Lavie P, Lavie L, Herer P. All-cause mortality in males with sleep apnoea syndrome: declining mortality rates with age. Eur Respir J. 2005; 25(3):514-520.

29. Bixler EO, Vgontzas AN, Ten Have T, Tyson K, Kales A. Effects of age on sleep apnea in men: I. Prevalence and severity. Am J Respir Crit Care Med. 1998;157(1):144-148.

30. Young T, Shahar E, Nieto FJ, et al. Predictors of sleep-disordered breathing in community-dwelling adults: the Sleep Heart Health Study. Arch Intern Med. 2002;162(8):893-900.

31. Duran J, Esnaola S, Rubio R, Iztueta A. Obstructive sleep apneahypopnea and related clinical features in a population-based sample of subjects aged 30 to 70 yr. Am J Respir Crit Care Med. 2001;163(3 Pt 1): 685-689. 
32. Malhotra A, Huang Y, Fogel R, et al Aging influences on pharyngeal anatomy and physiology: the predisposition to pharyngeal collapse. Am J Med. 2006;119(1):72.e9-72.e14.

33. Eikermann M, Jordan AS, Chamberlin NL, et al. The influence of aging on pharyngeal collapsibility during sleep. Chest. 2007;131(6): 1702-1709.

34. Redline S. Age-related differences in sleep apnea: generalizability of findings in older populations. In: Kuna ST, Surah PM, Remmers JE, editors. Sleep and Respiration in Aging Adults. New York: Elsevier; 1991:189-194.

35. Levy P, Ryan S, Oldenburg O, Parati G. Sleep apnoea and the heart. Eur Respir Rev. 2013;22(129):333-352.

36. Arzt M, Woehrle H, Oldenburg O, et al. Prevalence and predictors of sleep-disordered breathing in patients with stable chronic heart failure: The SchlaHF Registry. JACC Heart Fail. 2016;4(2):116-125.

37. Glasser M, Bailey N, McMillan A, Goff E, Morrell MJ. Sleep apnoea in older people. Breathe. 2011;7(3):248-256.

38. Lavie P, Lavie L. Unexpected survival advantage in elderly people with moderate sleep apnoea. J Sleep Res. 2009;18(4):397-403.

39. Haas DC, Foster GL, Nieto FJ, et al. Age-dependent associations between sleep disordered breathing and hypertension: importance of discriminating between systolic/diastolic hypertension and isolated systolic hypertension in the Sleep Heart Health Study. Circulation. 2005; 111(5):614-621.

40. Grote L, Hedner J, Peter JH. Sleep-related breathing disorder is an independent risk factor for uncontrolled hypertension. J Hypertens. 2000;18(6):679-685.

41. Glantz E, Thunstrom E, Herlitz J, et al. Occurrence and predictors of obstructive sleep apnea in a revascularized coronary artery disease cohort. Ann Am Thorac Soc. 2013;10(4):350-356.
42. Franklin KA, Sahlin C, Stenlund H, et al. Sleep apnoea is a common occurrence in females. Eur Respir J. 2013;41(3):610-615.

43. Young T, Finn L, Austin D, et al. Menopausal status and sleep-disordered breathing in the Wisconsin Sleep Cohort Study. Am J Respir Crit Care Med. 2003;167(9):1181-1185.

44. Bixler EO, Vgontzas AN, Lin HM, et al. Prevalence of sleep-disordered breathing in women: effects of gender. Am J Respir Crit Care Med. 2001; 163(3 Pt 1):608-613.

45. Grace SL, Abbey SE, Shnek ZM, Irvine J, Franche RL, Stewart DE. Cardiac rehabilitation I: review of psychosocial factors. Gen Hosp Psychiatry. 2002;24(3):121-126.

46. Arzt M, Young T, Finn L, et al. Association of sleep disordered breathing and the occurrence of stroke. Am J Respir Crit Care Med. 2005; 172(11):1447-1451.

47. Areias V, Romero J, Cunha K, et al. Sleep apnea-hypopnea syndrome and acute coronary syndrome an association not to forget. Rev Port Pneumol. 2012;18(1):22-28.

48. Deutsche Gesellschaft für Schlafforschung und Schlafmedizin (DGSM). S3-Leitlinie Nicht erholsamer Schlaf/Schlafstörungen - Kapitel "Schlafbezogene Atmungsstörungen”. Somnologie. 2017;20(Suppl 2):97-180.

49. Stopford E, Ravi K, Nayar V. The association of sleep disordered breathing with heart failure and other cardiovascular conditions. Cardiol Res Pract. 2013;2013:356280.

50. Hedner J, Bengtsson-Boström K, Peker Y, Grote L, Råstam L, Lindblad U. Hypertension prevalence in obstructive sleep apnoea and sex: a population-based case-control study. Eur Respir J. 2006;27(3): $564-570$.
Therapeutics and Clinical Risk Management

\section{Publish your work in this journal}

Therapeutics and Clinical Risk Management is an international, peerreviewed journal of clinical therapeutics and risk management, focusing on concise rapid reporting of clinical studies in all therapeutic areas, outcomes, safety, and programs for the effective, safe, and sustained use of medicines. This journal is indexed on PubMed Central, CAS,

\section{Dovepress}

EMBase, Scopus and the Elsevier Bibliographic databases. The manuscript management system is completely online and includes a very quick and fair peer-review system, which is all easy to use. Visit http://www.dovepress.com/testimonials.php to read real quotes from published authors. 